\title{
Trends in Behavioral Risk Factors Resulting in Premature Death in US from 2000-2015
}

\author{
Gavin J. Putzer, MD, PhD
}

Stetson University, Lynn Business School

Juan R. Jaramillo, PhD

Farmingdale State College, School of Business

*Corresponding Author: Gavin J. Putzer, MD, PhD, Stetson University, Lynn Business School

\begin{abstract}
Several of the leading causes of mortality - heart disease, cancer, diabetes, and stroke - are attributable at least partially to modifiable behavioral risk factors. These behavioral risk factors include smoking, poor diet/physical inactivity, and misuse of alcohol. We examined the trends of seven factors (tobacco smoking, misuse of alcohol, poor diet and physical inactivity, accidents, suicide, illicit use of drugs, and sexual behaviors) over the past 15 years in the United States with respect to avoidable deaths. Our data was extracted from the Centers for Disease Control and Prevention Wonder database. The mortality data utilizes the International Classification of Disease Codes, Tenth Edition, to track causes of death. There were several noteworthy trends in the data. Despite intensified attention to preventive health measures, avoidable deaths related to smoking, obesity (due to poor diet/lack of physical exercise), accidents, and sexually transmitted diseases, have remained relatively constant in the aggregate. In contrast, avoidable deaths attributable to illicit drug use, misuse of alcohol and suicide have dramatically increased. Between the year 2000 and 2015, illicit drug use has increased by more than 150\%, misuse of alcohol has increased by more than $35 \%$ and suicide by more than 50\%. These factors have also increased in varying degrees with respect to age cohorts. Many of the leading causes of mortality in the United States are chronic diseases and have genetic components, but they are also the major lifestyle diseases that trace tangibly to behavioral factors. The prospect for future declines in these diseases will most likely depend on a decrease in modifiable risk factors, media and policy advocacy, environmental interventions, improved education and lifestyle modifications.
\end{abstract}

\section{INTRODUCTION}

Many of the leading causes of mortality in the United States - heart disease, cancer, diabetes, chronic obstructive pulmonary disease and stroke - are chronic diseases with complex and interrelated connections and are attributable at least partially to modifiable risk factors. Some of the risk factors are genetic while others are modifiable and behavioral in nature such as smoking, poor diet/physical inactivity, and misuse of alcohol. Previous studies have demonstrated the adverse effects imposed by these factors on human health (Putzer, 2015; Putzer, 2004; Mokdad, 2004; Putzer, 2003; McGinnis, 1993).

There has been considerable progress regarding the understanding of the causes of chronic diseases (Remington, 2011). Consequently, human lifespans in the United States have been increasing over the past 50 years (NIA, 2015; McKenna, 2010). A female born in 2012 can expect on average to live until 81.2 years of age, while a male born in 2012 can expect on average to live until 76.4 years of age (NCHS, 2014). There are many available interventions that likely have contributed to this increase in longevity such as improvements in medical chronic disease diagnoses and treatments, public health preventive strategies, media and policy advocacy, environmental interventions, and an emphasis on healthy lifestyles (Molinari, 2004; McKenna, 2010; CDC, 2017; AHRQ, 2017; NCI, 2005; Remington, 2005).

Notwithstanding the progress from these advancements and improvements, there are still an estimated one million mortalities in the United States which may be considered premature or avoidable (Putzer, 2015; Keeney, 2008). Many of these avoidable deaths are 
attributed to behavioral risk factors such as tobacco smoking, misuse of alcohol, poor diet and physical inactivity which may lead to obesity (Lauby-Secretan, 2016; Bell, 2005; Siedel, 1999). Other factors include accidents (e.g., motor vehicle crashes), illicit use of drugs, risky sexual behaviors which may culminate in sexually transmitted diseases, and suicides (Keeney, 2008; Balia, 2008). Thus, we examined the trends regarding these seven factors over the past 15 years in the United States. Additionally, we stratified these seven factors via age cohorts to discern patterns in the factors and consequent premature mortalities.

\section{MeTHODS}

Our data was extracted from the Centers for Disease Control and Prevention (CDC) Wonder database. The database tracks causes of death within surveillance systems that are based on autopsy report codes known as the International
Classification of Diseases, Tenth Edition, (ICD10). Death certificates report a single underlying cause of mortality. The CDC Wonder data includes data from death certificates for US residents and it is easily accessible to view and examine online.

We calculated avoidable deaths for each behavioral risk factor and for each year from 2000-2015. This was accomplished employing a previously published methodology presented by Keeney in a study in 2008. We also differentiated for each of the seven behavioral risk factors - smoking, obesity, illicit drug use, alcohol misuse, sexually transmitted diseases, accidents and suicides - by age strata (less than one year of age, 1-4 years old, 5-14 years old, 15-24 years old, 25-34 years old, 35-44 years old, 45-54 years old, 55-64 years old, 65-74 years old, 75-84 years old, and greater than 85 years of age).

\section{RESUltS}

Table1. Avoidable Deaths from Behavioral Risk Factors

\begin{tabular}{|c|c|c|c|c|c|c|c|c|c|c|c|c|c|c|c|c|}
\hline \multicolumn{17}{|c|}{ Total Avoidable Deaths } \\
\hline & 2000 & 2001 & 2002 & 2003 & 2004 & 2005 & 2006 & 2007 & 2008 & 2009 & 2010 & 2011 & 2012 & 2013 & 2014 & 2015 \\
\hline Smoking & 341,355 & 339,046 & 339,748 & 337,348 & 326,717 & 333,443 & 322,164 & 320,243 & 329,721 & 320,847 & 322,160 & 324,139 & 325,956 & 332,424 & 330,371 & 340,373 \\
\hline Obesity & 434,376 & 431,547 & 432,285 & 428,399 & 416,813 & 417,867 & 409,305 & 405,570 & 405,776 & 400,073 & 402,461 & 404,179 & 407,120 & 411,778 & 415,957 & 425,417 \\
\hline Illicit Drugs & 9,398 & 10,026 & 12,201 & 13,502 & 13,984 & 15,073 & 17,619 & 16,572 & 15,892 & 15,430 & 15,157 & 16,154 & 16,869 & 18,318 & 20,240 & 23,742 \\
\hline Alcohol Misuse & 56,625 & 57,707 & 58,400 & 59,176 & 58,960 & 60,333 & 60,137 & 61,000 & 62,744 & 62,987 & 65,515 & 67,613 & 69,399 & 71,728 & 74,058 & 77,686 \\
\hline STDs & 20,584 & 20,241 & 20,219 & 19,769 & 19,135 & 18,824 & 18,650 & 18,015 & 17,151 & 16,346 & 15,444 & 15,121 & 14,853 & 14,882 & 14,632 & 14,495 \\
\hline Accidents & 38,096 & 38,998 & 40,578 & 40,658 & 41,208 & 41,819 & 42,229 & 41,972 & 39,478 & 37,233 & 37,135 & 37,567 & 38,568 & 38,422 & 39,068 & 41,225 \\
\hline Suicide & 29,343 & 30,607 & 31,645 & 31,477 & 32,428 & 32,629 & 33,292 & 34,592 & 36,030 & 36,897 & 38,357 & 39,508 & 40,596 & 41,143 & 42,769 & 44,189 \\
\hline Total & 929,778 & 928,172 & 935,076 & 930,329 & 909,246 & 919,988 & 903,395 & 897,964 & 906,793 & 889,813 & 896,230 & 904,281 & 913,361 & 928,695 & 937,096 & 967,127 \\
\hline
\end{tabular}

Table I shows total avoidable deaths of each of the seven risk factors. It spans the years 2000-2015.

Table2. Illicit Drug Use

\begin{tabular}{|c|c|c|c|c|c|c|c|c|c|c|c|c|c|c|c|c|}
\hline \multicolumn{17}{|c|}{ Illicit drugs } \\
\hline & 2000 & 2001 & 2002 & 2003 & 2004 & 2005 & 2006 & 2007 & 2008 & 2009 & 2010 & 2011 & 2012 & 2013 & 2014 & 2015 \\
\hline$<1$ & 6 & 4 & 9 & 4 & 4 & 2 & 8 & 6 & 6 & 7 & 8 & 7 & 9 & 9 & 6 & 9 \\
\hline $1-4$ & 8 & 10 & 10 & 9 & 11 & 11 & 16 & 19 & 24 & 19 & 19 & 27 & 21 & 16 & 21 & 32 \\
\hline $5-14$ & 13 & 13 & 17 & 13 & 21 & 24 & 24 & 31 & 17 & 17 & 26 & 17 & 14 & 13 & 6 & 21 \\
\hline $15-24$ & 773 & 895 & 1,114 & 1,350 & 1,499 & 1,507 & 1,851 & 1,807 & 1,762 & 1,630 & 1,654 & 1,820 & 1,787 & 1,869 & 1,989 & 2,291 \\
\hline $25-34$ & 1,867 & 1,913 & 2,246 & 2,496 & 2,542 & 2,819 & 3,388 & 3,194 & 3,165 & 3,155 & 3,223 & 3,656 & 3,935 & 4,272 & 4,998 & 6,170 \\
\hline $35-44$ & 3,725 & 3,789 & 4,489 & 4,621 & 4,458 & 4,467 & 4,935 & 4,332 & 3,924 & 3,559 & 3,386 & 3,434 & 3,552 & 3,860 & 4,305 & 5,156 \\
\hline $45-54$ & 2,497 & 2,792 & 3,461 & 3,942 & 4,211 & 4,761 & 5,555 & 5,140 & 4,880 & 4,671 & 4,419 & 4,500 & 4,625 & 4,781 & 4,982 & 5,482 \\
\hline $55-64$ & 389 & 463 & 664 & 835 & 997 & 1,209 & 1,504 & 1,722 & 1,730 & 1,974 & 2,060 & 2,258 & 2,446 & 2,919 & 3,234 & 3,715 \\
\hline $65-74$ & 71 & 92 & 125 & 159 & 165 & 178 & 225 & 224 & 275 & 280 & 253 & 323 & 372 & 457 & 568 & 722 \\
\hline $75-84$ & 30 & 36 & 33 & 42 & 55 & 57 & 78 & 60 & 65 & 77 & 67 & 74 & 76 & 72 & 83 & 95 \\
\hline$>85$ & 19 & 19 & 33 & 31 & 21 & 38 & 35 & 37 & 44 & 41 & 42 & 38 & 32 & 50 & 48 & 49 \\
\hline Total & 9,398 & 10,026 & 12,201 & 13,502 & 13,984 & 15,073 & 17,619 & 16,572 & 15,892 & 15,430 & 15,157 & 16,154 & 16,869 & 18,318 & 20,240 & 23,742 \\
\hline
\end{tabular}

Table II shows total avoidable deaths as a consequence of illicit drug use. It spans the years 20002015. It is stratified by age.

Table3. Alcohol Misuse

\begin{tabular}{|c|c|c|c|c|c|c|c|c|c|c|c|c|c|c|c|c|}
\hline \multicolumn{17}{|c|}{ Alcohol Misuse } \\
\hline & 2000 & 2001 & 2002 & 2003 & 2004 & 2005 & 2006 & 2007 & 2008 & 2009 & 2010 & 2011 & 2012 & 2013 & 2014 & 2015 \\
\hline$<1$ & 3 & 2 & 1 & - & - & - & - & 2 & 1 & - & 1 & $\cdot$ & 1 & $=$ & $=$ & $=$ \\
\hline $1-4$ & 1 & - & 2 & - & - & - & - & - & - & - & - & 2 & 1 & 2 & 1 & - \\
\hline 5-14 & 4 & 2 & 3 & 5 & 6 & 2 & 2 & 4 & 2 & 3 & - & 1 & 1 & 3 & - & 3 \\
\hline $15-24$ & 92 & 102 & 100 & 122 & 134 & 146 & 144 & 189 & 183 & 180 & 145 & 168 & 157 & 141 & 136 & 157 \\
\hline 25-34 & 631 & 616 & 577 & 575 & 573 & 521 & 602 & 683 & 763 & 716 & 861 & 866 & 975 & 1,064 & 1,201 & 1,373 \\
\hline $35-44$ & 5,242 & 5,205 & 5,078 & 4,931 & 4,617 & 4,519 & 4,407 & 4,209 & 4,241 & 4,115 & 4,085 & 4,066 & 3,981 & 4,123 & 4,272 & 4,528 \\
\hline $45-54$ & 10,303 & 11,147 & 11,188 & 11,672 & 11,816 & 12,086 & 12,287 & 12,594 & 12,835 & 13,028 & 13,316 & 13,616 & 13,506 & 13,281 & 13,256 & 13,517 \\
\hline $55-64$ & 10,753 & 10,880 & 11,527 & 12,123 & 12,468 & 13,284 & 13,707 & 14,471 & 15,221 & 15,903 & 17,022 & 18,220 & 19,068 & 20,001 & 21,138 & 22,081 \\
\hline $65-74$ & 11,956 & 11,950 & 11,731 & 11,655 & 11,472 & 11,458 & 11,253 & 11,479 & 11,939 & 11,922 & 12,504 & 12,788 & 13,724 & 14,778 & 15,629 & 16,891 \\
\hline $75-84$ & 11,104 & 11,238 & 11,465 & 11,350 & 11,206 & 11,364 & 11,074 & 10,720 & 10,644 & 10,394 & 10,499 & 10,575 & 10,630 & 10,750 & 10,882 & 11,285 \\
\hline$>85$ & 6,536 & 6,565 & 6,729 & 6,744 & 6,668 & 6,953 & 6,661 & 6,649 & 6,914 & 6,727 & 7,081 & 7,310 & 7,356 & 7,585 & 7,544 & 7,851 \\
\hline Total & 56,625 & 57,707 & 58,400 & 59,176 & 58,960 & 60,333 & 60,137 & 61,000 & 62,744 & 62,987 & 65,515 & 67,613 & 69,399 & 71,728 & 74,058 & 77,686 \\
\hline
\end{tabular}

Table III shows total avoidable deaths as a consequence of the misuse of alcohol. It spans the years 2000-2015. It is stratified into cohorts based on age. 


\begin{tabular}{|c|c|c|c|c|c|c|c|c|c|c|c|c|c|c|c|c|}
\hline \multicolumn{17}{|c|}{ Suicide } \\
\hline & 2000 & 2001 & 2002 & 2003 & 2004 & 2005 & 2006 & 2007 & 2008 & 2009 & 2010 & 2011 & 2012 & 2013 & 2014 & 2015 \\
\hline$<1$ & - & - & - & - & - & - & - & - & - & - & - & - & - & - & - & - \\
\hline 1-4 & - & - & - & - & - & - & - & - & - & - & - & - & - & - & - & - \\
\hline 5-14 & 307 & 279 & 264 & 250 & 285 & 272 & 219 & 184 & 222 & 265 & 274 & 287 & 311 & 395 & 428 & 413 \\
\hline $15-24$ & 3,994 & 3,971 & 4,010 & 3,988 & 4,316 & 4,212 & 4,189 & 4,140 & 4,298 & 4,371 & 4,600 & 4,822 & 4,872 & 4,878 & 5,079 & 5,491 \\
\hline $25-34$ & 4,792 & 5,070 & 5,046 & 5,065 & 5,074 & 4,990 & 4,985 & 5,278 & 5,300 & 5,320 & 5,735 & 6,100 & 6,216 & 6,348 & 6,569 & 6,947 \\
\hline $35-44$ & 6,562 & 6,635 & 6,851 & 6,602 & 6,638 & 6,550 & 6,591 & 6,722 & 6,703 & 6,677 & 6,571 & 6,599 & 6,758 & 6,551 & 6,706 & 6,936 \\
\hline $45-54$ & 5,437 & 5,942 & 6,308 & 6,481 & 6,906 & 6,991 & 7,426 & 7,778 & 8,287 & 8,598 & 8,799 & 8,858 & 8,862 & 8,621 & 8,767 & 8,751 \\
\hline $55-64$ & 2,945 & 3,317 & 3,618 & 3,843 & 4,011 & 4,210 & 4,583 & 5,069 & 5,465 & 5,808 & 6,384 & 6,521 & 6,929 & 7,135 & 7,527 & 7,739 \\
\hline $65-74$ & 2,292 & 2,432 & 2,463 & 2,335 & 2,279 & 2,344 & 2,384 & 2,444 & 2,796 & 2,917 & 2,974 & 3,179 & 3,367 & 3,794 & 4,110 & 4,201 \\
\hline 75-84 & 2,181 & 2,192 & 2,259 & 2,115 & 2,120 & 2,200 & 2,075 & 2,119 & 2,108 & 2,063 & 2,052 & 2,174 & 2,232 & 2,300 & 2,391 & 2,489 \\
\hline$>85$ & 833 & 769 & 826 & 798 & 799 & 860 & 840 & 858 & 851 & 878 & 968 & 968 & 1,049 & 1,121 & 1,192 & 1,222 \\
\hline Total & 29,343 & 30,607 & 31,645 & 31,477 & 32,428 & 32,629 & 33,292 & 34,592 & 36,030 & 36,897 & 38,357 & 39,508 & 40,596 & 41,143 & 42,769 & 44,189 \\
\hline
\end{tabular}

Table IV shows total avoidable deaths as a consequence of the misuse of alcohol. It spans the years 2000-2015. It is stratified by age.

\section{DISCUSSION}

McGinnis and Foege's (1993) original paper calculated the main external contributors to death. In 2004, Mokdad et al. updated the results and showed an increase in some contributors such as physical inactivity and poor diet. A study completed by Keeney (2008) demonstrated that personal choices affect mortality rates and he found through analysis that one million deaths could be attributable to personal decisions that could have been avoided if readily available alternative choices were made. We extended Keeney's work with a study in 2015 which showed the economic costs associated with lifestyle behaviors and the resulting premature mortalities (Putzer, 2015). A premature death may be defined as when an individual dies sooner than what would have been the case if a different choice had been made (Keeney, 2008; Putzer, 2015).

Despite intensified attention to public health preventive measures over the past 15 years, avoidable deaths due to smoking, obesity (due to poor diet/lack of physical exercise), accidents, and sexually transmitted diseases have not decreased in a sustained significant way. In contrast, avoidable deaths attributable to illicit drug use, misuse of alcohol and suicide have dramatically increased over this duration. Between the year 2000 and 2015, illicit drug use has increased by more than $150 \%$ (from 9,398 deaths to 23,742), misuse of alcohol has increased by more than $35 \%$ (from 56,625 deaths to 77,686 ), and suicide by more than $50 \%$ (from 29,343 deaths to 44,189).

The increase in illicit drug use and consequent premature mortalities was found across all age groups. The increase in aggregate numbers over the 15 year span is largest among the 25-34 age cohort $(1,867$ to 6,170$)$, while in percentage terms it is most abundant among 55-64 (over $850 \%$ ) and 65-74 (over 900\%) age cohorts, respectively. The increase in illicit drug use is plausibly related to the opioid abuse epidemic affecting the United States. Moreover, researchers at the CDC recently suggested that opioid deaths may be higher than reported because opioids suppress the body's immune system and can result in being classified on a death certificate as an infectious mortality (CDC, 2017). Opioids affect an individual's respiratory system causing breathing to be slow and shallow thereby diminishing the cough reflex and increasing the chance of pneumonia.

The increase in suicide rates and consequent premature mortalities was present across all age groups. The increase in aggregate numbers over the 15 year span is large among the $45-54$ age cohort $(5,437$ to 8,751) and the 55-64 age cohort $(2,945$ to 7,739$)$, while in percentage terms it is most abundant among 55-64 (over 160\%) age cohort. The increase in suicide may be related to the economic difficulties encountered among this age group during the Great Recession of 2007-2009. Many middle-aged individuals (4564 years of age) became unemployed with few economic opportunities available to pursue. Moreover, the majority of US citizens have very limited financial savings to withdraw upon during a crisis of any kind (AP-NORC, 2017). Furthermore, at the turn of the century the suicide rate may have been lower due to Surgeon General Dr. David Satcher's Call to Action regarding suicide and the consequent public health emphasis on reducing the number of suicides (NIH, 1999).

There are a few limitations in our study. It is often challenging to track causes of death within surveillance systems that are based on autopsy report codes known as ICD-10. Death 
certificates report a single underlying cause of mortality and there may be several comorbidities which affected the health status and led to the eventual death of an individual. Another limitation is that chronic diseases and causes of death associated with behavioral risk factors may also have a genetic component; thus, complicating the cause of mortality.

Future studies could examine these factors via other socio-cultural and socio-economic means (e.g., gender, ethnicity) to further elucidate the relations between behavioral factors and the leading causes of mortality. Many of the leading causes of mortality in the United States are chronic diseases and have genetic components, but they are also major lifestyle diseases that trace tangibly to behavioral factors. The prospect for future declines in these diseases will most likely depend on a decrease in modifiable risk factors, media and policy advocacy, environmental interventions, improved education and lifestyle modifications.

\section{REFERENCES}

[1] Putzer GJ, Jaramillo J. 2015. Premature Mortality Costs Associated with Lifestyle Factors among US Citizens. Review of Public Administration Management, 3:177. doi 10.4172/2315-7844.100017

[2] Putzer G, Roetzheim R, Ramirez AM, et al. 2004. Compliance with Recommendations for Lipid Management among Patients with Type 2 Diabetes in an Academic Family Practice. Journal of American Board of Family Practice; 17(2): 101-107.

[3] Mokdad AH, Marks JS, Stroup DF, Gerberding JL. 2004. Actual causes of death in the United States, 2000. Journal of the American Medical Association, 291: 1238-1245.

[4] Putzer GJ, Ramirez AM, Sneed K, et al. 2004. Prevelance with Patients with Diabetes Mellitus Type 2 Reaching the American Diabetes Association's Target Guidelines in a University Primary Care Setting. Southern Medical Journal; 97(2): 145-148.

[5] McGinnis JM, Foege WH. 1993. Actual Causes of death in the US. Journal of the American Medical Association, 270: 2207-2212.

[6] Molinari NAM. 2004. The Effect of Health Care on Population Health. The Lancet, 364: 1558-1560.
[7] National Institutes of Health. National Institute on Aging. Health and Aging. Available at https://www.nia.nih.gov/research/publication/gl obal-health-and-aging/living-longer

[8] McKenna M, Collins J. Current Issues and Challenges in Chronic Disease Control [Chapter 1]. In: Remington PL, Brownson R, Wegner MV, eds. Chronic Disease Epidemiology and Control. $3^{\text {rd }}$ edition. Washington, DC: American Public Health Association; 2010: 1-16.

[9] National Center for Health Statistics. Mortality in the United States, 2012. Data Brief No. 168. Available at https://www.cdc.gov/nchs/data/ databriefs/db168.pdf

[10] Centers for Disease Control. The Guide to Community Preventive Services. Available at http://www.thecommunityguide.org/index.html

[11] Agency for Healthcare Research and Quality. National Guideline Clearinghouse Available at http://www.guideline.gov/

[12] National Cancer Institute. Monograph 16: ASSIST. Shaping the Future of Tobacco Prevention and Control. Bethesda, MD: US Department of Health and Human Services, National Institutes of Health, National Cancer Institute; 2005

[13] Remington PL, Houston CA, Cook LC. Media interventions to promote tobacco control policies. In: Monograph 16: ASSIST. Shaping the Future of Tobacco Prevention and Control. Bethesda, MD: US Department of Health and Human Services, National Institutes of Health, National Cancer Institute; 2005:119-66.

[14] Keeney R. 2008. Personal Decisions are the Leading Causes of Death. Operations Research, 56: $1335-1347$

[15] Lauby-Secretan B, Scoccianti C, Loomis D, et al. 2016. Body Fatness and Cancer -Viewpoint of the IARC Working Group. New England Journal of Medicine, 375: 794-798.

[16] Bell CG, Walley AJ, Froguel P. 2005. The Genetics of Human Obesity. Nat Rev Genetics, 6: 22-234.

[17] Siedel JC. 1999. The Burden of Obesity and its Sequelae. Disease Management Health Outcomes, 1: 13-21.

[18] Balia S, Jones AM. 2008. Mortality, Lifestyle, and Socio-Economic status. Journal of Health Economics, 27: 1-26.

[19] Centers for Disease Control and Prevention. Opioid Overdose. Available at https://www cdc .gov/drugoverdose/ 
[20] The Associated Press and NORC Center for Public Affairs Research. University of Chicago. Poll: Two-thirds of US would struggle to cover $\$ 1,000$ crisis. Available at http://www.apnorc. org/news-media/Pages/News+Media/Poll-Twothirds-of-US-would-struggle-to-cover-\$1,000crisis.aspx
[21] National Library of Medicine. National Institutes of Health. The Surgeon General's Call to Action to Prevent Suicide. Available at https://profiles.nlm.nih.gov/ps/retrieve/Resourc eMetadata/NNBBBH

Citation: Gavin, J. Putzer, and Juan R. Jaramillo. "Trends in Behavioral Risk Factors Resulting in Premature Death in US from 2000-2015." International Journal of Research in Business Studies and Management, vol 4, no. 4, 2017, pp. 8-12.

Copyright: (C) 2017 Gavin, J. Putzer et al. This is an open-access article distributed under the terms of the Creative Commons Attribution License, which permits unrestricted use, distribution, and reproduction in any medium, provided the original author and source are credited. 